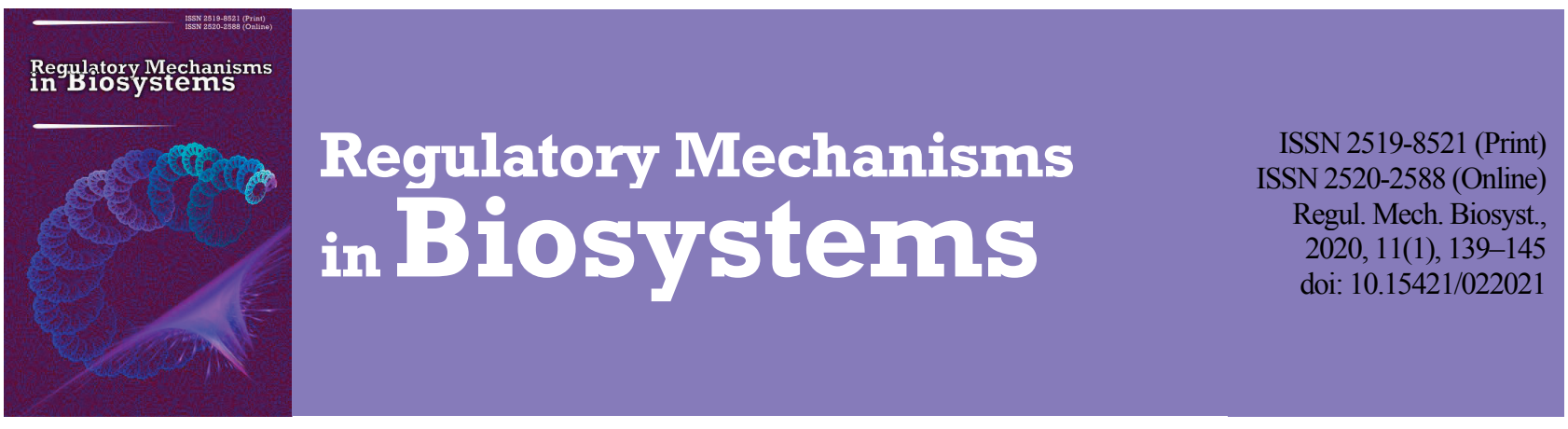

\title{
Simultaneous and sequential influence of metabolite complexes of Lactobacillus rhamnosus and Saccharomyces boulardii and antibiotics against poly-resistant Gram-negative bacteria
}

\author{
O. Y. Isayenko*, O. V. Knysh*, O. V. Kotsar**, T. N. Ryzhkova***, G. I. Dyukareva**** \\ *I. I. Mechnikov Institute of Microbiology and Immunology of National Academy of Medical Sciences of Ukraine, Kharkiv, Ukraine \\ **Kharkiv National Medical University, Kharkiv, Ukraine \\ ***Kharkiv State Zooveterinary Academy, Kharkiv, Ukraine \\ ****Kharkiv College of Trade and Economics of Kyiv National University of Trade and Economics, Kharkiv, Ukraine
}

Article info

Received 20.03.2020

Received in revised form 15.04.2020

Accepted 18.04.2020

I. I. Mechnikov Institute

of Microbiology and Immunology

of National Academy of Medical

Sciences of Ukraine, Pushkinska st.,

14/16, Kharkiv, 61057, Ukraine.

Tel.: +38-099-43-41-830.

E-mail:elisaenko@ukr.net

Kharkiv National Medical University,

Nauky avenne, 4, Kharkiv, 61022,

Ukraine. Tel.: +38-099-98-21-089.

E-mail:knysh_oksana@ukr.net

Kharkiv State Zooveterinary Academy

Akademichna st., 1, Mala Danylivka,

Kharkiv region, 62341, Ukraine

Tel.: +38-096-38-46-058.

E-mail:rujkova.ua@gmail.com

Kharkiv State University

of Food Technology and Trade,

Klochkivska st., 333,

Kharkiv, 61051, Ukraine.

\section{Introduction}

Complications during the treatment of simple infectious diseases occur more and more often due to significant increase in the resistance of etiologically significant pathogens to antibacterial preparations (Andrzejczuk et al., 2019; Elbediwi et al., 2019; Palchykov et al., 2019; Perdikouri et al., 2019; Koulenti, 2020). Increase in the amount of antibiotic-resistant strains of different species of microorganisms raises concerns in many countries and stimulates scientists to develop alternative preparations (Chaudhary, 2016; Richardson, 2017; Pizzolato-Cezar et al., 2019). At the stages of search for optimum methods of obtaining biologically active substances, one should take into consideration the necessity of further development of medical preparations against poly-resistant pathogens and of reducing the development of resistance to them. Also, a complex approach is needed to solve the important problem of projecting new technologies of the production of medical preparations and development of a new class of additional/alternative preparations of metabolic type on the base of the products of vital activity of probiotic origin due to their ability to increase the sensitivity of pathogenic strains to the existing antibacterial preparations and their efficient use in combination with antibiotics.
Isayenko, O. Y., Knysh, O. V., Kotsar, O. V., Ryzhkova, T. N., \& Dyukareva, G. I. (2020). Simultaneous and sequential influence of metabolite complexes of Lactobacillus rhamnosus and Saccharomyces boulardii and antibiotics against

For the first time the poly-resistant strains of Gram-negative microorganisms were studied for the sensitivity to combequential influence of metabolic complexes of Lactobacillus rhamnosus GG and Saccharomyces boulardii, obtained by the author's method without using the growth media, with antibiotics. The synergic activity of antidiffusive method of Kirby-Bauer. During the sequential method of testing (at first the microorganisms were incubated with increase in the diameters of the zones of growth inhibition of Pseudomonas aeruginosa PR to the typical antibiotics (gentamicin, amicyl, ciprofloxacin, cefotaxime) and non-typical (lincomycin, levomycetin) depending on the tested combinations. acin, cefotaxime, levomycetin. Susceptibility of Lelliottia amnigena (Enterobacter amnigenus) PR increased to levofloxacin, lincomycin. The zones of growth inhibition of Klebsiella pneumoniae PR increased to gentamicin, amicyl, tetracycline, ceffiaxon sequential combination of antibiotics with separate metabolic complexes of $L$. rhamnosus and $S$. boulardii, and also their combination (to 15.2, 20.2 and $15.4 \mathrm{~mm}$ respectively) compared whe the mechanism of action of antibacterial preparation. Metabolic complexes of L. rhamnosus GG and S. boulardii, due to of the development of resistance of microorganisms, and are therefore promising candidates for developing "accompanying medications" to antibiotics and antimicrobial preparations of new generation.

Keywords: sacharomycetes; lactobacteria; potentioning of the action of antibiotics; increase in the susceptibility of bacteria.

A number of researchers have determined high antimicrobial properties of the derivatives and metabolites of Lactobacillus rhamnosus GG against a broad spectrum of microorganisms (Kaktcham et al., 2011; Kaktcham et al., 2012; Daba \& Saidi, 2015; Frickmann et al., 2018; Goyal \& Kannan, 2018). The effect of supernatant of $L$. rhamnosus GG was confirmed against vitality of $S$. aureus and $S$. epidermidis (Frickmann et al., 2018) Metabolites of Lactobacillus rhamnosus $1 \mathrm{~K}$ exerted activity towards Listeria innocua, Staphylococcus aureus, Salmonella typhi, Bacillus cereus, Streptococcus mutans, Escherichia coli, Pseudomonas aeruginosa, Klebsiella pneumoniae, Shigella flexneri (Kaktcham et al., 2011; Kaktcham et al., 2012). The supernatant of Lactobacillus rhamnosus GG displayed antibacterial properties versus Salmonella typhimurium (Keersmaecker[2006). The inhibiting effect of the mentioned supernatant of the lactobacteria was confirmed against S. typhimurium after $4 \mathrm{~h}$ of incubation (Goyal, 2018). Metabolites of probiotic strains are known for the activity towards $P$. aeruginosa and Escherichia coli (Daba \& Saidi, 2015).

Notable antibacterial and anti-biofilm properties were displayed by supernatant of $S$. boulardii versus $S$. aureus, S. pyogenes, E. coli, K. pneumoniae, E. aerogens, S. typhi, A. baumannii, P. auroginosa, P. mirabilis (Sahib et al., 2017). According to other data, metabolites of $S$. bou- 
lardii bactericidially affect $S$. aureus and exert no activity towards $E$. coli (Stefania et al., 2017). According to the data of the authors (Arqués, 2011; Montiel et al., 2015), combined application of the derivatives of different strains of species of probiotic microorganisms is successful. Their research revealed that combined use of reuterin and lactoferrin exhibited higher antimicrobial activity towards microorganisms compared with their individual effect (Montiel et al., 2015). Strong synergic effect was confirmed during addition of reuterin and nisin/lactiken 481/enterocin AS-48 (Arqués, 2011). Their bactericidal activity was determined against Escherichia coli O157:H7, Salmonella enterica, Yersinia enterocolitica, Aeromonas hydrophila and Campylobacter jejuni. Increase in antimicrobial action was observed during combined testing of nisin and reuterin versus Staphylococcus aureus (Arqués, 2011).

Other publications report synergic activity of combination of vitality products of probiotic microorganisms and antibiotics against pathogenic agents (Tong, 2014; Bolosov, 2017; Lainson, 2017). Combined use of nisin (antibiotic which is formed by Streptococcus lactis) with antibacterial preparations (penicillin, ampicillin, gentamicin, kanamycin, roxithromycin, streptomycin, vancomycin, chloramphenicol, cefuroxime, cefazolin, ceftriaxone, cefepime, ciprofloxacin, imipenem, linezolid) was accompanied by increase in their antibacterial effect. Most notable antimicrobial properties were exerted by nisin with penicillin or chloramphenicol versus three strains of $E$. faecalis. Serious damage to $E$. faecalis caused by combinations of any antibiotic with nisin were confirmed (Tong, 2014). Tests of combinations of peptide substances with oxacillin displayed effectiveness versus Staphylococcus aureus, especially an antibiotic-resistant strain, compared with using them alone (Lainson, 2017). The study of combined influences of antimicrobial peptide and antibacterial preparations revealed different levels of synergic activity depending on the medical combinations (Bolosov, 2017). Interaction of antibiotics and metabolic complexes of lactobacteria and sacharomycetes, obtained by cultivating microbial cells of probiotics in their structural components, tested against polyresistant Gram-negative microorganisms has not studied before. Likewise, the influence of structural components and metabolites of Lactobacillus rhamnosus GG and Saccharomyces boulardii obtained by the author's method on the susceptibility of Gram-negative pathogens to antibacterial preparations has not been studied before.

The study demonstrates increase in the susceptibility of poly-resistant strains of microorganisms to antimicrobial preparations, recreated using the sequential influence of the products of vitality of lactobacteria and sacharomycetes and antibiotics on Gram-negative bacteria. At first, the selected pathogens contacted the structural components and metabolites of probiotic strains of Lactobacillus rhamnosus GG and Saccharomyces boulardii obtained by cultivation of the primary producers in their ultrasound disintegrates. Then, we studied the sensitivity of polyresistant Gram-negative microorganisms previously maintained in the researched substances to the antibacterial preparations. Also, the study presents combined use of metabolic complexes of lactobacteria and saccharomycetes with antibacterial preparations as a result of simultaneous effect on the poly-resistant Gram-negative microorganisms.

The objective of this study was substantiation of the possibility of using metabolic complexes of L. rhamnosus GG and $S$. boulardii for developing "accompanying medications" for antibiotics and antimicrobial preparations of new generation by studying their combined simultaneous and sequential effect with antibacterial preparations on poly-resistant Gram-negative microorganisms.

\section{Materials and methods}

The structural components of probiotic fungi and bacteria were obtained by exposure of suspensions of $S$. boulardii (with probiotic preparation BULARDI ${ }^{\circledR}$, Schonen, Switzerland) and L. rhamnosus GG (with symbiotic PREEMA ${ }^{\circledR}$, Schonen, Switzerland) to low-frequency waves using low-frequency generator GZ-109 loaded on the circular piezoceramic converters of PZT type in energy-saving mode (Isajenko et al., 2017; Isajenko et al., 2018). Metabolic complexes (metabolites, vitality products) of Lactobacillus rhamnosus GG and S. boulardii were obtained by cultivating suspensions of lactobacteria and/or saccharomycetes in their structural components according to the author's method (Isa- yenko et al., 2017; Isayenko et al., 2018). The surveyed material of the filtrates of probiotic strains of microorganisms (six samples): filtrates of the structural components of lactobacteria $(\mathrm{L})$ and saccharomycetes $(\mathrm{S})$; filtrates of the cultures of lactobacteria (ML), saccharomycetes (MS) grown in their structural components; filtrates of the common cultures of lactobacteria with saccharomycetes (MLS) grown in the structural components of lactobacteria; filtrates of the cultures of saccharomycetes (LS) grown in the structural components of lactobacteria.

Test-cultures: polyresistant Gram-negative strains of Pseudomonas aeruginosa PR, Acinetobacter baumannii PR, Klebsiella pneumoniae PR, Lelliottia amnigena (Enterobacter amnigenus) PR (from the collection of microorganisms of the Laboratory of Prevention of Infections of the Respiratory Tracts of the Institute of Microbiology and Immunology of the National Academy of Medical Sciences, Kharkiv). For the study, we used $24 \mathrm{~h}$ cultures cultivated in the standardised growth media (Atlas, 2010). The suspensions of the microorganisms were prepared using $0.9 \%$ normal saline of the solution of sodium chloride. Optimum density of the samples was prepared in accordance with the McFarland scale, using the rules of Densi-La-Meter (PLIVA-Lachema Diagnostika, (Czech Republic)). Synchronization of the cultures was performed in hypothermal conditions in $4 \pm 1^{\circ} \mathrm{C}$.

The set of the antibacterial preparations for the evaluation of susceptibility of the microorganisms was formed in accordance with the following methodological recommendations and orders: Order of Ukraine on approval of methodological instructions "Determination of sensitivity of microorganisms to antibacterial drugs" No 167, 2007 and The European Committee on Antimicrobial Susceptibility Testing, 2019. We used one representative of the different groups of antimicrobial preparations: drugs-of-choice, additional and "non-standard" preparations which are usually not used against diseases caused by the surveyed pathogens. The study on the influence of metabolic complexes of Lactobacillus rhamnosus GG and Saccharomyces boulardii on the sensitivity of test-cultures to antibiotics was performed according to the generally accepted methods of the order of Ukraine on approval of methodological instructions "Determination of sensitivity of microorganisms to antibacterial drugs" No 167. The difference was the preliminary incubation of the bacteria with the studied substances of L. rhamnosus GG and $S$. boulardii. Therefore, the suspensions of test-strains with the optical density of 5.0 units according to the McFarland's scale were added to the filtrates which contained the metabolites and structural components of the cells of probiotic microorganisms (tested samples) or up to $0.9 \%$ of the sodium chloride solution (control samples) in 1:1 proportion. The experimental and control samples were grown during $1 \mathrm{~h}$ at the temperature of $35 \pm 1{ }^{\circ} \mathrm{C}$, and then the optical density of experimental and control samples was adjusted to 0.5 units of McFarland's scale in accordance with order of Ukraine on approval of methodological instructions "Determination of sensitivity of microorganisms to antibacterial drugs" No 167. The material from the samples was inoculated onto the Mueller-Hinton agar, the surface with inoculations were covered by disks with antibiotics, incubated at the temperature of $35^{\circ} \mathrm{C}$ for $24 \mathrm{~h}$. The results were recorded by measuring the zones of inhibition of growth of microorganisms around the disks with antibiotics. The described method consists of consequent use of the studied substances with antibacterial preparations in relation to the selected pathogens.

Combined simultaneous influence of metabolic complexes of $L$. rhamnosus GG and $S$. boulardii and antibacterial preparations on poly-resistant Gram-negative strains was studied using the disk-diffusion method of Kirby-Bauer modified by Jagriti Sharma (Sharma et al., 2014; Sharma \& Chauhan, 2014; Sharma \& Chauhan, 2015). To ensure the maximum absorption, the standard disks with antibacterial preparations were kept in filtrates (experimental samples) or in $0.9 \%$ solution of sodium chloride (control samples) during $1 \mathrm{~h}$ in $37 \pm 1{ }^{\circ} \mathrm{C}$. The experimental and control disks were put onto the preprepared Petri dishes with solid growth medium of Muller Hinton which was previously inoculated with suspensions of microorganisms (with optical density of 0.5 units according to McFarland scale) and kept for $3 \mathrm{~h}$ in $37 \pm 1{ }^{\circ} \mathrm{C}$. The dishes with suspensions of bacteria and disks were kept in $4 \pm 1{ }^{\circ} \mathrm{C}$ for $1 \mathrm{~h}$ (to ensure the diffusion) and incubated in $37 \pm 1{ }^{\circ} \mathrm{C}$ for $24 \mathrm{~h}$. The zones of inhibition of the growth of pathogens in the experimental and control samples were 
measured and compared. The results were analyzed in Statistica 8.0 (StatSoft Inc., USA) program. The calculations were made for the mean arithmetic (x) and standard deviation of the mean arithmetic (SD). The reliability of the differences between the obtained data were determined by the single-factor dispersion analysis ANOVA. The difference was considered probable in the experimental samples in relation to the control ones at the values of $\mathrm{P}<0.05$ taking into account the Bonferroni correction.

\section{Results}

The influence of the structural components and metabolites of probiotic strains of lactobacteria and saccharomycetes on the susceptibility of poly-resistant Gram-negative microorganisms to antibacterial prepa- rations revealed that the surveyed filtrates mostly increase the susceptibility of the selected bacteria to the antibiotics (Fig. 1,2).

Increase in the diameters of the growth inhibition zones of Pseudomonas aeruginosa PR (after preliminary treatment with metabolite complexes) to gentamicin was observed by $0-4.2 \pm 0.8 \mathrm{~mm}$, amicyl by $2.0-6.6 \mathrm{~mm}$, ciprofloxacin - by $0.4-3.0 \pm 0.7 \mathrm{~mm}$, cefotaxime - by $0.2-3.2 \pm 1.9 \mathrm{~mm}$ depending on the surveyed combinations. Statistically reliable increase was observed in the susceptibility of P. aeruginosa PR to non-typical antibiotics: by $13.2-20.2 \mathrm{~mm}$ to lincomycin ( $\mathrm{P}<0.001)$, by $9.2-11.0 \mathrm{~mm}$ to levomycetin $(\mathrm{P}<0.05)$. No increase in the susceptibility of the surveyed microorganism to combined sequential influence of the surveyed substances with erythromycin was observed (Fig. 1a).
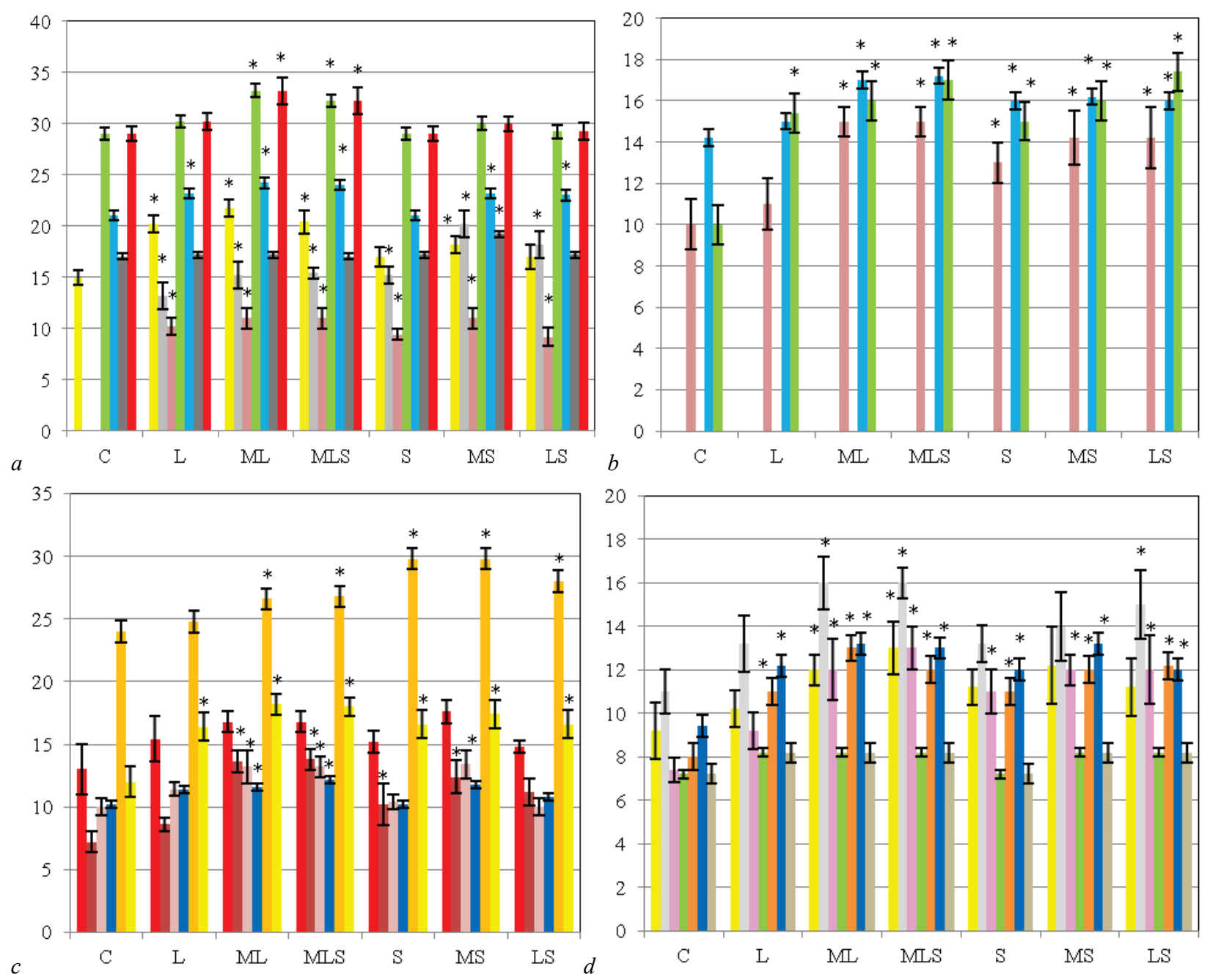

Fig. 1. Diameters of growth inhibition zones (mm) of poly-resistant strains of Pseudomonas aeruginosa PR (a), Acinetobacter baumannii PR (b), Klebsiella pneumoniae PR (c), Lelliottia amnigena (Enterobacter amnigenus) PR (d) to antibacterial preparations (gentamicin - red, cefotaxime light blue, levomycetin - light Bordeaux, amicyl - yellow, ciprofloxacin - green, lincomycin - grey, erythromycin - black, ceftriaxone - orange, tetracycline - dark brown, ampicillin - dark blue, amoxiclav - light brown, levofloxacin - raspberry) after sequential influence of metabolite complexes of probiotic strains of Lactobacillus rhamnosus $\mathrm{GG}$ i Saccharomyces boulardii (CU, $\mathrm{x} \pm \mathrm{SD}, \mathrm{n}=5$ ): $\mathrm{K}$ - control (solution of sodium chloride), $\mathrm{L}$ - filtrate of microbial cells of L. rhamnosus GG treated with ultrasound (structural components), ML - metabolites (metabolite compounds) of lactobacteria obtained by growing primary producer in its ultrasound disintegrates, MLS - combination of metabolites of saccharomycetes and lactobacteria obtained by growing primary producers in ultrasound disintegrates of lactobacteria, $\mathrm{S}$ - filtrate of microbial cells of $S$. boulardii treated by ultrasound (structural components), MS - metabolites (metabolite compounds) of saccharomycetes obtained by growing primary producer in its

ultrasound disintegrates, LS - metabolites (metabolite compounds) of saccharomycetes obtained by growing primary producer in ultrasound disintegrates of lactobacteria; * - difference in the experimental samples as compared with the control was statistically significant at $(\mathrm{P}<0.05)$

Lower sensitivity during sequential use of metabolic complexes and antibacterial preparations was exhibited by poly-resistant strain Acinetobacter baumannii PR. We observed increase in the diameter of growth inhibition zones of the pathogen for the combination with ciprofloxacin (by $5.2-7.4 \mathrm{~mm}, \mathrm{P}<0.05$ ), cefotaxime (by $0.8-3.0 \mathrm{~mm}, \mathrm{P}<0.05$ ), levomycetin (by 1.0-5.0 mm, P $<0.05$, Fig. 1b). Effect of the substances of lactobacteria and sacharomycetes on the susceptibility of Klebsiella pneumoniae PR to antibiotics was accompanied by increase in the growth inhibition zones of the microorganisms to gentamicin by $2.4-5.6 \mathrm{~mm}$, amicyl - by $5.2-7.2 \mathrm{~mm}(\mathrm{P}<0.05)$, tetracycline - by $2.0-7.8 \mathrm{~mm}$, ceftriaxone - by $1.4-6.0 \mathrm{~mm}$. The lowest increase in susceptibility of K. pneumoniae PR was observed for ampicillin (by 1.0-2.8 mm) and 
non-typical antibiotic levomycetin (by 1.0-4.2 mm, Fig. 1c). The substances of $L$. rhamnosus GG and $S$. boulardii increased the susceptibility of Lelliottia amnigena (Enterobacter amnigenus) PR to levofloxacin by $1.8-5.6 \mathrm{~mm}$, lincomycin $-2.2-5.0 \mathrm{~mm}$, ceftriaxone $-3.0-5.0 \mathrm{~mm}$, ampicillin $-2.6-3.8 \mathrm{~mm}$. The zones of inhibition of microorganisms' growth after the sequential influence of the metabolite complexes with amoxiclav mostly did not change (Fig. 1d).

Different increase in susceptibility of the surveyed poly-resistant bacteria to antibiotics probably depended on the individual sensitivity of strains of test-culture and antimicrobial activity of combinations of metabolite complexes with antibiotics. The highest increase in the susceptibility of the selected poly-resistant pathogens to the antibiotics occur- red during the use of combination with ML, MS and MLS due to their sequential influence (up to $15.2 \pm 1.3,20.2 \pm 1.3$ and $15.4 \pm 0.5 \mathrm{~mm}$ respectively, $\mathrm{P}<0.05$ ).

During simultaneous use of metabolite complexes with antibacterial preparations, the increase in the antimicrobial activity also occurred to different degrees (Fig. 2). Maximum increase in inhibition of growth of microorganisms, similarly to the sequential influence, was observed for combination of antibiotics with ML, MS and MLS (to $12.2 \pm 1.3,15.2 \pm$ 1.5 and $13.0 \pm 1.6 \mathrm{~mm}$ respectively, $\mathrm{P}<0.05)$. Differences manifested in the lower increase in the diameters of the zones of growth inhibition among the selected pathogens during combined simultaneous influence of the substances of lactobacteria and saccharomycetes with antibiotics.
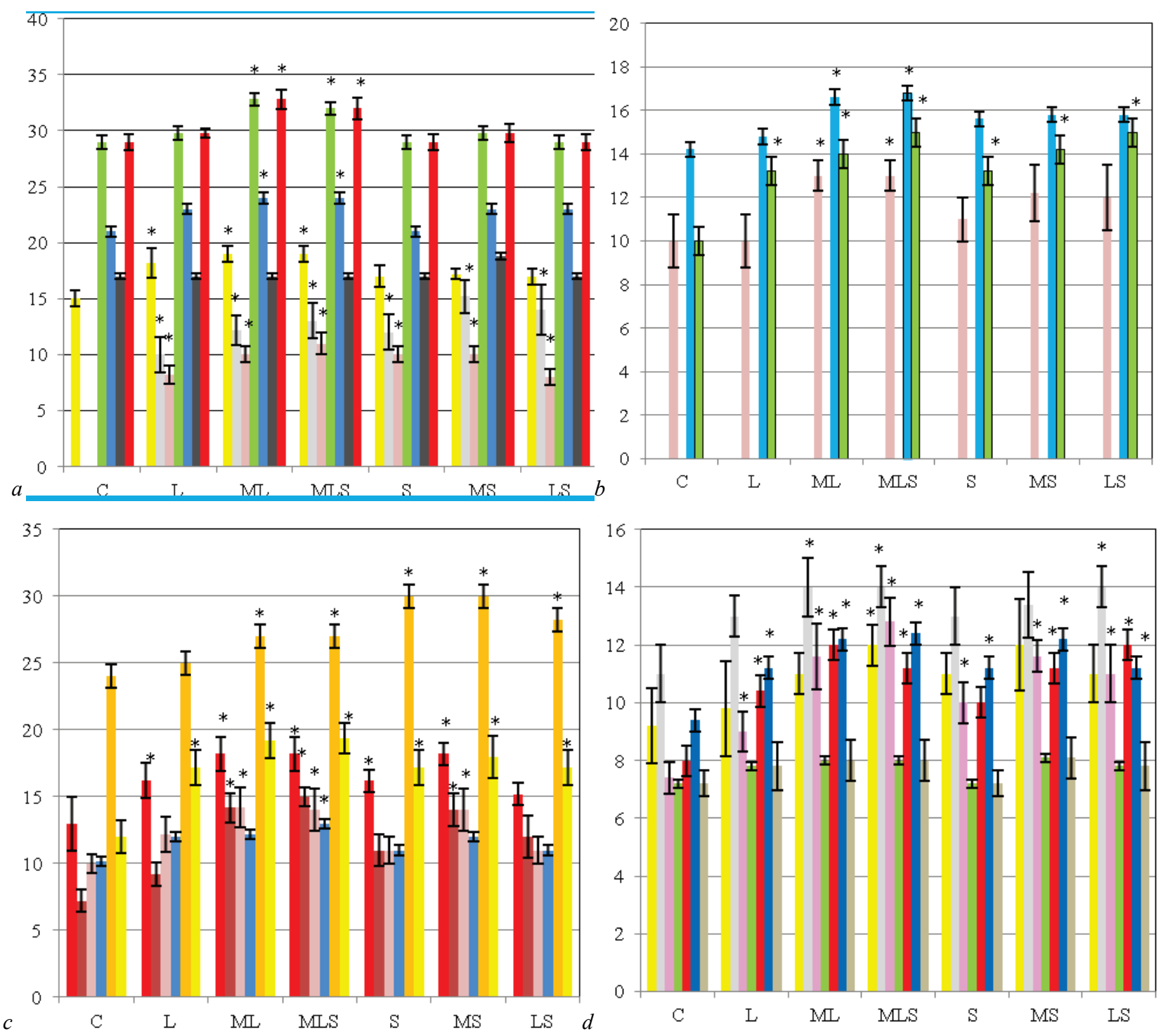

Fig. 2. Diameters of growth inhibition zones (mm) of poly-resistant strains of Pseudomonas aeruginosa PR (a), Acinetobacter baumannii PR (b), Klebsiella pneumoniae PR (c), Lelliottia amnigena (Enterobacter amnigenus) PR (d) to antibacterial preparations (gentamicin - red, cefotaxime light blue, levomycetin - light Bordeaux, amicyl - yellow, ciprofloxacin - green, lincomycin - grey, erythromycin - black, ceftriaxone - orange, tetracycline - dark brown, ampicillin - dark blue, amoxiclav - light brown, levofloxacin - raspberry) after simultaneous influence of metabolite complexes of probiotic strains of Lactobacillus rhamnosus GG and Saccharomyces boulardii (CU, $\mathrm{x} \pm \mathrm{SD}, \mathrm{n}=5$ ): $\mathrm{K}$ - control (solution of sodium chloride), $\mathrm{L}$ - filtrate of microbial cells of $L$. rhamnosus GG treated by ultrasound (structural components), $\mathrm{ML}$ - metabolites (metabolite compounds) of lactobacteria obtained by growing primary producer in its ultrasound disintegrates, MLS - combination of metabolites of saccharomycetes and lactobacteria obtained by growing primary producers in ultrasound disintegrates of lactobacteria, $\mathrm{S}$ - filtrate of microbial cells of

$S$. boulardii treated by ultrasound (structural components), MS - metabolites (metabolite compounds) of saccharomycetes obtained by growing

primary producer in its ultrasound disintegrates, LS - metabolites (metabolite compounds) of saccharomycetes obtained by growing primary producer in ultrasound disintegrates of lactobacteria; * - difference in the experimental samples compared with the control is statistically significant $(\mathrm{P}<0.05)$

The ability of metabolite complexes to increase the susceptibility of poly-resistant microorganisms to antibiotics and to act synergically was accompanied by the manifestation of the susceptibility to amicyl, cefota- xime in the moderately-resistant strain of $P$. aeruginosa and to gentamicin in the moderately-resistant strain of $K$. pneumonia (at simultaneous and sequential applications, Table 1). During sequential influence of different 
surveyed substances, the resistant strain of $K$. pneumonia displayed susceptibility to amicyl (all samples), levomycetin (all samples, except L, S), tetracycline (MLS). During simultaneous use of samples of L, S with amicyl, the culture K. pneumonia exhibited moderate resistance, and MLS with tetracycline - resistance, indicating less notable increase in the susceptibility of poly-resistant pathogens to antibiotics when using this method. Under the influence of different surveyed substances, levomycetinand cefotaxime-resistant strain of $A$. baumannii exhibited moderate resistance regardless of the method of their application. Ciprofloxacin-resistant A. baumannii demonstrated moderate resistance only with sequential combination with samples of ML and MLS.

The result of the conducted work confirmed the efficiency of the sequential and simultaneous use of metabolic complexes of $L$. rhamnosus GG and $S$. boulardii with antimicrobial preparations. Under the effect of the substances of lactobacteria and saccharomycetes, the diameter of the zones of inhibition of growth of poly-resistant strains produced by antibiotics increased to different extents. The most significant inhibition of growth of microorganisms was seen during their sequential combination, regardless of the classification of the selected antimicrobial preparations. The antibacterial medical preparations taken to the experiment are identified to different groups, differing in mechanisms of action towards microbial cells of bacteria and are used in therapeutic practice as best-choice medications, additional and non-standard preparations (have no clinical significance). Regardless of the mechanism of the action of antibacterial preparation and the way of influence, the maximum increase in the diameter of the zone of inhibition of growth of poly-resistant Gram-negative bacteria was observed with combination of the medical preparations with samples of ML, MS and MLS.

\section{Table 1}

Evaluation of changes in susceptibility (by diameter of growth inhibition zones) of poly-resistant microorganisms to combined sequential and simultaneous applications of antibacterial preparations with metabolite complexes of Lactobacillus rhamnosus GG and Saccharomyces boulardii obtained by the author's method $(n=5)$

\begin{tabular}{|c|c|c|c|c|c|c|c|c|c|c|c|c|c|c|c|c|c|c|}
\hline \multirow[b]{3}{*}{$\begin{array}{c}\text { Tested } \\
\text { substances }\end{array}$} & \multicolumn{9}{|c|}{ Sequential influence } & \multicolumn{9}{|c|}{ Simultaneous influence } \\
\hline & \multicolumn{3}{|c|}{ P.aeruginosa } & \multicolumn{3}{|c|}{ K. pneumoniae } & \multicolumn{3}{|c|}{ A. baumannii } & \multicolumn{3}{|c|}{ P.aeruginosa } & \multicolumn{3}{|c|}{ K. pneumoniae } & \multicolumn{3}{|c|}{ A. baumannii } \\
\hline & 危 & 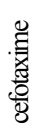 & 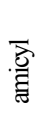 & $\begin{array}{l}\text { 总 } \\
\text { 劳 } \\
\text { 总 }\end{array}$ & 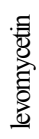 & 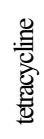 & 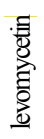 & 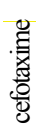 & 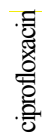 & . & 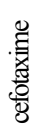 & 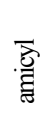 & 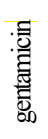 & 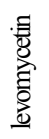 & 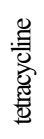 & 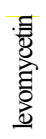 & 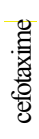 & 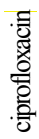 \\
\hline $\mathrm{C}$ & $\mathrm{m}$ & $\mathrm{m}$ & $\mathrm{r}$ & $\mathrm{m}$ & $\mathrm{r}$ & $\mathrm{r}$ & $\mathrm{r}$ & $\mathrm{r}$ & $\mathrm{r}$ & $\mathrm{m}$ & $\mathrm{m}$ & $\mathrm{r}$ & $\mathrm{m}$ & $\mathrm{r}$ & $\mathrm{r}$ & $\mathrm{r}$ & $\mathrm{r}$ & $\mathrm{r}$ \\
\hline $\mathrm{L}$ & $\mathrm{s}$ & $\mathrm{s}$ & $\mathrm{s}$ & $\mathrm{s}$ & $\mathrm{r}$ & $\mathrm{r}$ & $\mathrm{r}$ & $\mathrm{m}$ & $\mathrm{r}$ & $\mathrm{s}$ & $\mathrm{s}$ & $\mathrm{m}$ & $\mathrm{s}$ & $\mathrm{r}$ & $\mathrm{r}$ & $\mathrm{r}$ & $\mathrm{r}$ & $\mathrm{r}$ \\
\hline ML & $\mathrm{s}$ & $\mathrm{s}$ & $\mathrm{s}$ & $\mathrm{s}$ & $\mathrm{m}$ & $\mathrm{r}$ & $\mathrm{m}$ & $\mathrm{m}$ & $\mathrm{m}$ & $\mathrm{s}$ & $\mathrm{s}$ & $\mathrm{s}$ & $\mathrm{s}$ & $\mathrm{m}$ & $\mathrm{r}$ & $\mathrm{m}$ & $\mathrm{m}$ & $\mathrm{r}$ \\
\hline MLS & $\mathrm{s}$ & $\mathrm{s}$ & $\mathrm{s}$ & $\mathrm{s}$ & $\mathrm{m}$ & $\mathrm{m}$ & $\mathrm{m}$ & $\mathrm{m}$ & $\mathrm{m}$ & $\mathrm{s}$ & $\mathrm{s}$ & $\mathrm{s}$ & $\mathrm{s}$ & $\mathrm{m}$ & $\mathrm{r}$ & $\mathrm{m}$ & $\mathrm{m}$ & $\mathrm{r}$ \\
\hline $\mathrm{S}$ & $\mathrm{s}$ & $\mathrm{m}$ & $\mathrm{s}$ & $\mathrm{s}$ & $\mathrm{r}$ & $\mathrm{r}$ & $\mathrm{m}$ & $\mathrm{m}$ & $\mathrm{r}$ & $\mathrm{s}$ & $\mathrm{m}$ & $\mathrm{m}$ & $\mathrm{s}$ & $\mathrm{r}$ & $\mathrm{r}$ & $\mathrm{r}$ & $\mathrm{m}$ & $\mathrm{r}$ \\
\hline MS & $\mathrm{s}$ & $\mathrm{s}$ & $\mathrm{S}$ & $\mathrm{s}$ & $\mathrm{m}$ & $\mathrm{r}$ & $\mathrm{m}$ & $\mathrm{m}$ & $\mathrm{m}$ & $\mathrm{S}$ & $\mathrm{s}$ & $\mathrm{s}$ & $\mathrm{s}$ & $\mathrm{m}$ & $\mathrm{r}$ & $\mathrm{r}$ & $\mathrm{m}$ & $\mathrm{r}$ \\
\hline LS & $\mathrm{s}$ & $\mathrm{s}$ & $\mathrm{s}$ & $\mathrm{s}$ & $\mathrm{r}$ & $\mathrm{r}$ & $\mathrm{m}$ & $\mathrm{m}$ & $\mathrm{m}$ & $\mathrm{s}$ & $\mathrm{s}$ & $\mathrm{m}$ & $\mathrm{m}$ & $\mathrm{r}$ & $\mathrm{r}$ & $\mathrm{r}$ & $\mathrm{m}$ & $\mathrm{r}$ \\
\hline
\end{tabular}

Note: $\mathrm{C}$ - control (solution of sodium chloride), L - filtrate of microbial cells of L. rhamnosus GG treated by ultrasound (structural components), ML - metabolites (metabolite compounds) of lactobacteria obtained by growing primary producer in its ultrasound disintegrations, MLS - combination of metabolites of saccharomycetes and lactobacteria obtained by growing primary producer in ultrasound disintegrates of lactobacteria obtained by growing primary producers in ultrasound disintegrates of lactobacteria, S - filtrate of microbial cells of S. boulardii treated by ultrasound (structural components), MS - metabolites (metabolite compounds) obtained by growing primary producer in its ultrasound disintegrates, LS - metabolites (metabolite compounds) of saccharomycetes obtained by growing primary producer in ultrasound disintegrates of lactobacteria, $\mathrm{s}$ - susceptible, $\mathrm{m}$ - moderately resistant, $\mathrm{r}$ - resistant.

\section{Discussion}

The results from simultaneous influence of metabolic complexes of L. rhamnosus GG and S. boulardii with antibacterial preparations showed overall increase in their antimicrobial activity against most selected strains and different combinations. Synergy of using the substances of lactobacteria and saccharomycetes with medical preparations manifested in potentiating (preparations intensify antimicrobial effects of one another), sometimes indifferent action (effect of one substance does not depend on the presence of other) (Paramonova \& Kharchenko, 2012). The presented results confirm the studies of other authors on synergic activity of the simultaneous effect of derivatives and products of vitality of microorganisms used in combination with antibacterial preparations. Therefore, during the combined influence of polymyxin B and gramicidin S formed by Aneurinibacillus migulanus (Bacillus brevis), an increase was observed in antimicrobial activity of antibiotic versus poly-resistant strains of $P$. aerugino$s a$ and their biofilms (Berditsch et al., 2015). Combined use of lipopeptide Bacillomycin D and amphotericin B intensified anti-Candida effect against Candida albicans (Tabbene et al., 2016). Combining cells of Lactobacillus rhamnosus, Saccharomyces boulardii, Streptococcus faecalis and Lactobacillus acidophilus with antibiotics increased antimicrobial activity of aztreonam, amikacin, meropenem, ciprofloxacin towards reference and circulating strains of Pseudomonas (Sharma \& Chauhan, 2014). Potentiating of amoxicillin/clavulanic acid was exerted by $S$. boulardii and $L$. rhamnosus against $E$. coli, and amoxicillin/clavulanic acid, azithromycin, ciprofloxacin - L. rhamnosus, S. boulardii, S. faecalis and L. acidophilus against S. aureus (Sharma et al., 2014; Sharma \& Chauhan, 2015). The presented results of our studies correspond with these authors regarding identification of individual sensitivity of test cultures to synergic action of the surveyed substances and antibacterial preparations, and also use of the same method of determining their antimicrobial activity - mod- ified disk-diffusion method of Kirby-Bauer. Results of combined use of derivatives and products of vitality of probiotics with antimicrobial preparations are also confirmed by the following data (Dosler, 2012). Antimicrobial activity of nisin (product of vitality of Streptococcus lactis) alone and in combination with antibiotics (daptomycin, vancomycin, linezolid, ampicillin, erythromycin) was determined towards Gram-positive bacteria (methicillin-susceptible $S$. aureus and methicillin-resistant Enterococcus faecalis). Synergic effect occurred most often using combination of nisin and ampicillin against $S$. aureus and nisin with daptomycin against strains of $E$. faecalis. Comparing experimental data presented in this article with our studies, we should note that high antimicrobial activity was determined for separate influence of surveyed substances and more notable synergic activity in combination with antibacterial preparations towards pathogens.

In the next study the increase in activity was determined for testing combination of nisin with polymyxin versus biofilm-forming strains of Pseudomonas (Field et al., 2019). Other authors confirmed the efficacy of combining nisin with penicillin and chloramphenicol against biofilms of $S$. aureus SA113 and S. pseudintermedius DSM21284 (Field et al., 2019). Synergic effect was seen for use of combinations of nisin and amoxicillin, penicillin, streptomycin, tetracycline, ceftiofin against Streptococcus suis (swine pathogen, transmission to human is possible) (Lebel et al., 2013). The studies confirmed in vitro activity of combination of lantabiotic - actagardine with different antibiotics towards Clostridium difficile: actagardin with ramoplanin act partly synergically/additively against $61.5 \%$ of strains of $C$. difficile, actagardin-metronidazole $-54 \%$, and actagardin-vancomycin $-38 \%$ of strains (Mathur et al., 2013). Also partial synergic effect was determined for combination of Lacticin 3147 (Lactococcus lactis) and polymyxin against S. aureus (Draper et al., 2013). Combined use of plantaricins E, F, J and K with antibiotics exhibited anti-Candida activity (Sharma \& Srivastava, 2014). 
Combining Durancin 61 produced by Enterococcus durans with vancomycin was accompanied by synergic activity against MRSA $S$. aureus ATCC 700699 (Hanchi et al., 2017). Lantabiotic - suicin 3908 (with Streptococcus suis) additively interacted with amoxicillin or penicillin versus S. suis (Vaillancourt et al., 2015). And suicin 90-1330 (from non-virulent $S$. suis strain serotype 2 ) had high homology with lantabiotic nisin U (LeBel G et al., 2015). The results of our work on the different extents of the manifestation of synergic effect depending on the activity of combinations and individual susceptibility of microorganisms during their simultaneous application correlate well with the studies of these authors. The increase in antimicrobial activity which we observed in combination of antibiotics with the surveyed substances coincides with the presented results of synergic effect of metabolic complexes of lactobacteria and sacharomycetes with antimicrobial preparations. The presented combinations have advantages due to the possibility of using antibacterial preparations in lower concentrations as a result of inducement of antimicrobial activity, and therefore decrease in their toxicity for the organism.

Results of the efficacy of simultaneous influence of the surveyed substances and antibiotics are confirmed by the data of our previous studies. Synergic activity of metabolite complexes of L. rhamnosus and $S$. boulardii with ampicillin, azithromycin was observed towards polyresistant Gram-positive microorganisms Staphylococcus aureus, S. haemoliticus, Enterococcus faecalis, Corynebacterium xerosis. Increase in antimicrobial activity of levofloxacin was observed against Staphylococcus and Enterococcus.

Higher efficacy of the sequential influence of metabolite complexes of $L$. rhamnosus and S. boulardii and antibacterial preparations which we saw in our study confirm the data presented in our previous publications. The highest increase in susceptibility of Corynebacterium spp. tox + substances of lactobacteria and saccharomycetes was observed towards penicillins, carbapenem and glycopeptides antibiotics. Lower increase in the sensitivity of toxigenic strains was determined to aminoglycosides, macrolides and quinolones during sequential influence of the surveyed preparations and antibiotics. During simultaneous use, we observed less notable effect: maximum increase in antimicrobial activity of macrolides was seen over the influence of MLS, and in the activity of beta-lactams during the influence of ML. The determined variation in extent of manifestation of combined action of metabolite complexes and antibiotics depended on the selected combinations, way of influence on microorganism, activity of the filtrates of L. rhamnosus GG and $S$. boulardii and individual sensitivity of test-cultures and was regardless of classification of the mechanism of action of antibacterial preparations, as reported in this study. For example, fluoroquinolones (ciprofloxacin) inhibit the synthesis of bacterial DNA, beta-lactams, to which cephalosporins (cefotaxime) are identified, inhibit biosynthesis of cellular wall constituents, and aminoglycosides inhibit bacterial synthesis of protein. It was determined that under the influence of metabolic complexes of L. rhamnosus GG and S. boulardii, the increase in sensitivity of poly-resistant strains occurred to a different extent to different groups of antibacterial preparations. Mechanism of action of aminoglycosides, in particular amycil, is due to the inhibition of synthesis of protein in cells of microorganisms. It bonds to ${ }^{30} \mathrm{~S}$ subunit of ribosome, and prevents the formation of complex of transport and matrix RNA, blocks synthesis of protein, and impairs the synthesis of cytoplasmic membrane of bacterium. Moderately amycil-resistant strains of $P$. aeruginosa $\mathrm{PR}, K$. pneumoniae PR were susceptible, and $K$. pneumoniae PR exhibited susceptibility also to gentamicin. During the use of the surveyed substances even in combination with non-typical antibiotics, increase was observed in the susceptibility of Pseudomonas aeruginosa PR: increases in the zones of inhibition of pathogen's growth was determined for lincomycin and levomycetin. Lincosamides (lincomycin) are used mostly for treating patients with infections caused by Grampositive microorganisms. By their action mechanism, they inhibit bacterial synthesis of protein similarly to chloramphenicols (levomycetin).

Other authors have also confirmed increase in susceptibility of clinical isolates of Klebsiella pneumoniae to antibacterial preparations while using peptides (Ribeiro et al., 2015). The research revealed antimicrobial and anti-biofilm activities of DJK-5, DJK-6 i 1018 against five strains of $K$. pneumoniae. Concentrations of peptides required for prevention of formation of biofilm of the surveyed test-cultures was lower than MIC for planktonic forms of the reported strains. Under their influence, degradation of pre-formed two-day biofilm was determined. Combination of DJK-6 and $\beta$-lactam antibiotics prevented growth of planktonic and biofilm forms of K. pneumoniae C1825971. Peptide DJK-6 was observed to increase the ability of meropenem to eradicate pre-formed biofilms of this strain by at least 16 times. The authors suggest using DJK-6 for intensification of the activity of $\beta$-lactames, particularly meropenem, in order to treat $K$. pneumoniae-caused infections. Our results correlate with the data of this work regarding synergic effect of biologically active substances with antibacterial preparations and differ by the survey of sequential and simultaneous use of the structural components and metabolites of Lactobacillus rhamnosus GG and Saccharomyces boulardii for the inducement of susceptibility of several poly-resistant strains and confirmation of the synergic activity with different antibiotics. Increase in bioavailability is of great scientific significance due to the possibilities of using lower concentrations of antibacterial preparations, reducing the terms of their use and slowing the development of resistance of microorganisms.

\section{Conclusions}

During the combined use of metabolite complexes of $L$. rhamnosus and $S$. boulardii and antibacterial preparations, we determined increase in the diameter of zones of inhibition of growth of poly-resistant strains while using antibiotics. Synergic effect was seen both over sequential influence (due to increase in the susceptibility of microorganisms to antibiotics) and during simultaneous use (due to increase in antimicrobial activity). Increase in the diameters of zones of inhibition of growth of Pseudomonas aeruginosa PR during the sequential method of testing was seen for typical antibiotics (gentamicin - by 0-4.2 mm, amycil - by $2.0-6.6 \mathrm{~mm}$, ciprofloxacin - by $0.4-3.0 \mathrm{~mm}$, cefotaxime - by $0.2-$ $3.2 \mathrm{~mm}$ ) and non-typical (lincomycin by 13.2-20.2 mm), levomycetinby $9.2-11.0 \mathrm{~mm}$ ) depending on the surveyed combinations. Acinetobacter baumannii PR exhibited lower susceptibility: growth inhibition was seen for combination with ciprofloxacin - by $5.2-7.4 \mathrm{~mm}$, cefotaxime - by $0.8-3.0 \mathrm{~mm}$, levomycetin - by $1.0-5.0 \mathrm{~mm}$. Susceptibility of Lelliottia amnigena (Enterobacter amnigenus) PR to levofloxacin increased by $1.8-5.6 \mathrm{~mm}$, lincomycin - by $2.2-5.0 \mathrm{~mm}$. The zones of inhibition of growth of Klebsiella pneumoniae PR increased with use of gentamicin by $2.4-5.6 \mathrm{~mm}$, amicyl - by $5.2-7.2 \mathrm{~mm}$, tetracycline by $2.0-7.8 \mathrm{~mm}$, ceftriaxone - by $1.4-6.0 \mathrm{~mm}$. Maximum efficacy was determined during combining the medical preparations with separate metabolic complexes of L. rhamnosus (ML) and S. boulardii (MS), and also their combination (MLS), regardless of the mechanism of action of antibacterial preparation. Higher increase in antimicrobial activity occurred during sequential combining of antibiotics with ML, MS and MLS (to $15.2 \pm 1.3,20.2 \pm 1.3$ and $15.4 \pm 0.5 \mathrm{~mm}$ respectively, $\mathrm{P}<$ 0.05 ) compared with their simultaneous use (to $12.2 \pm 1.3,15.2 \pm 1.5$ and $13.0 \pm 1.6 \mathrm{~mm}$ respectively, $\mathrm{P}<0.05$ ) for all the surveyed polyresistant pathogens. Metabolic complexes of Lactobacillus rhamnosus GG and Saccharomyces boulardii obtained using the author's method, due to increase in susceptibility of etiologically significant pathogens, can allow the necessary concentration of antibiotic to be decreased by prolonging the term of their use and slowing the possibility of the development of resistance of microorganisms, and also due to synergic activity with antibacterial preparations of different groups, making them promising candidates for the development of "accompanying medications" with possibility of additional therapy of infectious diseases of different etiology.

\section{References}

Andrzejczuk, S., Kosikowska, U., Chwiejczak, E., Stępień-Pyśniak, D., \& Malm, A. (2019). Prevalence of resistance to $\beta$-lactam antibiotics and bla genes among commensal Haemophilus parainfluenzae isolates from respiratory microbiota in Poland. Microorganisms, 7(10), e427. 
Arqués, L. (2011). Combined effect of reuterin and lactic acid bacteria bacteriocins on the inactivation of food-borne pathogens in milk. Food Control, 22(3-4), $457-461$.

Atlas, R. (2010). Handbook of microbiological media. Boca Raton, London, New York.

Berditsch, M., Jäger, T., Strempel, N., Schwartz, T., Overhage, J., \& Ulrich, A. (2015). Synergistic effect of membrane-active peptides polymyxin B and gramicidin $\mathrm{S}$ on multidrug-resistant strains and biofilms of Pseudomonas aeruginosa. Antimicrobial Agents and Chemotherapy, 59(9), 5288-5296.

Bolosov, I., Kalashnikov, A., Panteleev, P., \& Ovchinnikova, T. (2017). Analysis of synergistic effects of antimicrobial peptide arenicin-1 and conventional antibiotics. Bulletin of Experimental Biology and Medicine, 162(6), 765-768.

Chaudhary, A. (2016). A review of global initiatives to fight antibiotic resistance and recent antibiotics' discovery. Acta Pharmaceutica Sinica B, 6, 552-556.

Daba, H., \& Saidi, S. (2015). Detection of bacteriocin-producing lactic acid bacteria from milk in various farms in North-East Algeria by a new procedure. Agronomy Research, 13, 907-918.

De Keersmaecker, S. C. J. (2006). Strong antimicrobial activity of Lactobacillus rhamnosus GG against Salmonella typhimurium is due to accumulation of lactic acid. FEMS Microbiology Letters, 259(1), 89-96.

Dosler, S., \& Gerceker, A. (2012). In vitro activities of antimicrobial cationic peptides; melittin and nisin, alone or in combination with antibiotics against Gram-positive bacteria. Journal of Chemotherapy, 24(3), 137-143.

Draper, L., Cotter, P., Hill, C., \& Ross, R. (2013). The two peptide lantibiotic lacticin 3147 acts synergistically with polymyxin to inhibit Gram negative bacteria. BMC Microbiology, 13, 212-220.

Elbediwi, M., Li, Y., Paudyal, N., Pan, H., Li, H., Xie, S., Rajkovic, A., Feng, Y., Fang, W., Rankin, S., \& Yue, M. (2019). Global burden of colistin-resistant bacteria: Mobilized colistin resistance genes study (1980-2018). Microorganisms, 7(10), 461-479.

Field, D., O' Connor, R., Cotter, P., Ross, R., \& Hill, C. (2016). In vitro activities of nisin and nisin derivatives alone and in combination with antibiotics against Staphylococcus biofilms. Frontiers in Microbiology, 7, e508.

Field, D., Seisling, N., Cotter, P., Ross, R., \& Hill, C. (2016). Synergistic nisinpolymyxin combinations for the control of Pseudomonas biofilm formation. Frontiers in Microbiology, 26(7), e1713.

Frickmann, H., Klenk, C., Warnke, P., Redanz, S., \& Podbielski, A. (2018). Influence of probiotic culture supernatants on in vitro biofilm formation of staphylococci. European Joumal of Microbiology and Immunology, 8(4), 119-127.

Goyal, N., \& Kannan, K. (2018). Inhibition of Salmonella typhimurium by cell free supernatant of probiotic Lactobacillus rhamnosus GG. International Journal of Probiotics and Prebiotics, 13(1), 37-44.

Hanchi, H., Hammami, R., Gingras, H., Kourda, R., Bergeron, M., Ben Hamida, J., Ouellette, M., \& Fliss, I. (2017). Inhibition of MRSA and of Clostridium difficile by durancin 61A: Synergy with bacteriocins and antibiotics. Future Microbiology, 12, 205-212.

Isayenko, O. (2019). Protydyfteriyni vlastyvosti strukturno-metabolitnykh kompleksiv probiotychnykh shtamiv laktobakteriy i sakharomitsetiv u testakh in vitro ta in vivo [Anti-diphtheria properties of structural-metabolites complexes of Lactobacillus and Saccharomyces probiotic strains]. Fiziologichnyj Zhurnal, 65(6), 51-61 (in Ukrainian).

Isayenko, O. (2019). Synergistic activity of filtrates Lactobacillus rhamnosus GG and Saccharomyces boulardii and antibacterial preparations against Corynebacterium spp. Regulatory Mechanisms in Biosystems, 10(4), 245-250.

Isayenko, O., Knysh, O., Fal'ko, O., Prokopyuk, V., \& Prokopyuk, O. (2019). Tsytotoksychnost' strukturno-metabolitnykh kompleksiv Lactobacillus rhamnosus GG ta Saccharomyces boulardii [Cytotoxicity structural-metabolitic complexes of Lactobacillus rhamnosus GG and Saccharomyces boulardii]. Fiziologichnyj Zhurnal, 65(5), 35-41 (in Ukrainian).

Kaktcham, P. M., Zambou, N. F., Atiya, A., \& Fozia, A. (2012). Characterization of bacteriocin produced by Lactobacillus rhamnosus $1 \mathrm{~K}$ isolated from traditionally fermented milk in the western highlands region of Cameroon. International Journal of Biology, 4(2), 149-155.

Kaktcham, P. M., Zambou, N. F., Fonteh, A. F., Sieladie, D. V., \& Tchouanguep, M. F. (2011). Characterization of bacteriocin produced by Lactobacillus rhamnosus $1 \mathrm{~K}$ isolated from traditionally fermented milk in the western highlands region of Cameroon. New York Science Journal, 4(8), 121-128.
Koulenti, D., Xu, E., Song, A., Sum Mok, I. Y., Karageorgopoulos, D. E., Armaganidis, A., Tsiodras, S., \& Lipman, J. (2020). Emerging treatment options for infections by multidrug-resistant gram-positive microorganisms. Microorganisms, $8(2)$, e191.

Lainson, J., Daly, S., Triplett, K., Johnston, S., Hall, P., \& Diehnelt, C. (2017). Synthetic antibacterial peptide exhibits synergy with oxacillin against MRSA. ACS Medicinal Chemistry Letters, 8, 853-857.

Lebel, G., Piché, F., Frenette, M., Gottschalk, M., \& Grenier, D. (2013). Antimicrobial activity of nisin against the swine pathogen Streptococcus suis and its synergistic interaction with antibiotics. Peptides, 50, 19-23.

Lebel, G., Vaillancourt, K., Frenette, M., Gottschalk, M., \& Grenier, D. (2014). Suicin 90-1330 from a nonvirulent strain of Streptococcus suis: A nisinrelated lantibiotic active on gram-positive swine pathogens. Applied and Environmental Microbiology, 80(17), 5484-5492.

Mathur, H., O'Connor, P. M., Hill, C., Cotter, P. D., \& Ross, R. P. (2013). Analysis of anti-Clostridium difficile activity of thuricin $\mathrm{CD}$, vancomycin, metronidazole, ramoplanin, and actagardine, both singly and in paired combinations. Antimicrobial Agents and Chemotherapy, 57(6), 2882-2886.

Montiel, R. (2015). Reuterin, lactoperoxidase, lactoferrin and high hydrostatic pressure on the inactivation of food-borne pathogens in cooked ham. Food Control, $51,122-128$

Palchykov, V. A., Zazharskyi, V. V., Brygadyrenko, V. V., Davydenko, P. O., Kulishenko, O. M., Borovik, I. V., Chumak, V., Kryvaya, A., \& Boyko, O. O. (2019). Bactericidal, protistocidal, nematodicidal properties and chemical composition of ethanol extract of Punica granatum peel. Biosystems Diversity, 27(3), 300-306.

Perdikouri, E., Arvaniti, K., Lathyris, D., Kiouti, F., Siskou, E., Haidich, A., \& Papandreou, C. (2019). Infections due to multidrug-resistant bacteria in oncological patients: Insights from a five-year epidemiological and clinical analysis. Microorganisms, 7(9), e277.

Pizzolato-Cezar, L., Okuda-Shinagawa, N., \& Machini, M. (2019). Combinatory therapy antimicrobial peptide-antibiotic to minimize the ongoing rise of resistance. Frontiers in Microbiology, 10, e1703.

Ribeiro, S., de la Fuente-Núñez, C., Baquir, B., Faria-Junior, C., Franco, O., \& Hancock, R. (2015). Antibiofilm peptides increase the susceptibility of carbapenemase-producing Klebsiella pneumoniae clinical isolates to $\beta$-lactam antibiotics. Antimicrobial Agents and Chemotherapy, 59(7), 3906-3912.

Richardson, L. (2017). Understanding and overcoming antibiotic resistance. PLoS Biology, 15(8), e2003775.

Sahib, F., Nawfal, H. Aldujaili, N., \& Alrufae, M. (2017). Biosynthesis of silver nanoparticles using saccharomyces boulardii and study their biological activities. European Journal of Pharmaceutical and Medical Research, 4(9), 65-74.

Sharma, A., \& Srivastava, S. (2014). Anti-Candida activity of two-peptide bacteriocins, plantaricins ( $\mathrm{Pln} \mathrm{E} / \mathrm{F}$ and $\mathrm{J} / \mathrm{K}$ ) and their mode of action. Fungal Biology, 118(2), 264-275

Sharma, J., \& Chauhan, D. S. (2014). Inhibition of Pseudomonas aeruginosa by antibiotics and probiotics combinations - in vitro study. European Journal of Experimental Biology, 4(6), 10-14.

Sharma, J., \& Chauhan, D. S. (2015). In vitro study on the role of probiotic strains in potentiation of antimicrobial activity against Staphylococcus aureus. International Journal of Pharmacy and Life Sciences, 6(1), 4161-4165.

Sharma, J., Chauhan, D. S., \& Goyal, A. (2014). Enhancement of antimicrobial activity of antibiotics by probiotics against Escherichia coli - an in vitro study. Advances in Applied Science Research, 5(6), 14-18.

Stefania, D., Miranda, P., Diana, M., Claudia, Z., Pagiotti, R., \& Pietrella, D. (2017). Antibiofilm and antiadhesive activities of different synbiotics. Journal of Probiotics and Health, 5(3), 182-191.

Tabbene, O., Azaiez, S., Di Grazia, A., Karkouch, I., Ben Slimene, I., Elkahoui, S., Alfeddy, M. N., Casciaro, B., Luca, V., Limam, F., \& Mangoni, M. L. (2016). Bacillomycin D and its combination with amphotericin B: Promising antifungal compounds with powerful antibiofilm activity and wound-healing potency. Journal of Applied Microbiology, 120(2), 289-300.

Tong, Z., Zhang, Y., Ling, J., Ma, J., Huang, L., \& Zhang, L. (2014). An in vitro study on the effects of nisin on the antibacterial activities of 18 antibiotics against Enterococcus faecalis. PLoS One, 9(2), e89209.

Vaillancourt, K., LeBel, G., Frenette, M., Gottschalk, M., \& Grenie, D. (2015). Suicin 3908, a new lantibiotic produced by a strain of Streptococcus suis serotype 2 isolated from a healthy carrier pig. PLoS One, 10(2), e0117245. 